\section{Understanding living systems}

Ordre et Dynamique du Vivant: Chemins de la Biologie Moleculaire. By A. Danchin. Pp. 381. (Editions du Seuil: Paris, 1978.)

THE object of this book, as specified by the author himself, is to emphasise the contribution of our knowledge of molecular phenomena to the understanding of a living system as a whole, including the human brain processes. The book opposes those theories which purport that our understanding of the way a whole organism is working is a specific property of the system and cannot result from the analytical study of each of its components, and concludes that the fundamental properties of a living system are the direct consequences of the properties of its constitutive molecules.

The author chooses several "reduction levels". He first examines the general characteristics of a cell and the modalities of its development. $\mathrm{He}$ then considers a second reduction level, the chromosomal one, and includes the rudiments of genetics and indispensable notions on cellular division. In the third and most extensive part, he comes to the fundamental reduction level, the molecular one. After recounting the nature of the interactions between atoms and between molecules, he gives a clear account of the processes of molecular biology-that is, an account of the mechanism of protein synthesis and its regulation-and has succeeded very well in describing the basis of these processes clearly and concisely.

The last part is the most original. It begins with an examination of the nature of viruses and an analysis of the possibility of their synthesis, continues with a study of genetical manipulation experiments already accomplished or to be considered in the future, and ends with an examination of the feasibility of hypotheses concerning the origin of life and the evolution of species. He explains the relationship between phylogenesis and variations in the amino acid sequences of proteins and why he conceives the evolution of species as the development of controls: some fluctuations in the hereditary programme favour the adjustment of the system to external conditions and are therefore integrated in the descendants. There must be a limit, however, to what can be recorded in a genetical programme, and non-hereditary modifications will occur. These individual processes, which the author calls epigenesis, allow adjustment to the external medium. The epigenesis of the nervous network is given as a good example.
This book is aimed to non-specialists. My main regret is that the author's care in explaining clearly the physicochemical mechanisms of the biological processes to non-initiates did not allow him to develop his own ideas more extensively. Nevertheless, this interesting book succeeds well in its stated purpose of showing that the working

\section{Regulators of plant growth}

Natural Plant Growth Inhibitors and Phytohormones. By V. I. Kefeli. Pp. 278. (Junk: The Hague and Boston, 1978.) Dfi.90; $\$ 44$.

THE known and accepted hormonal regulators of plant growth and development comprise the auxins, the gibberellins, the cytokinins, abscisic acid and (perhaps) ethylene. Each of these substances has a clearly defined range of physiological activities, and it is the interplay of these activities which results in the coordination and regulation of the various processes and development. Some plant physiologists, however, believe that this is not enough, asserting that the precise regulation of a process may only be achieved through a balance between stimulatory and inhibitory actions. Given this premise, it is inescapable logic that the auxins, gibberellins and cytokinins, whose actions on cell growth and differentiation are predominantly stimulatory, should be balanced by endogenous, growth-inhibitory substances. As almost any substance, at sufficiently high concentration, will inhibit plant growth, it is obviously very easy to find such inhibitors; it is, on the other hand, and equally obviously, extremely difficult to prove that such growthinhibitory substances actually act, endogenously, to inhibit growth. Dr Kefeli is a protagonist of the inhibitor camp, and he uses this book in a forceful and single-minded attempt to convince the reader that his view is correct.

The book is based on the author's work carried out at the Timiryazev Institute of Plant Physiology of the USSR Academy of Sciences between 1961 and 1967, and its most valuable contribution lies in providing, for Western scientists, in English, a readable and well documented summary of work which is not easily available from published literature. It is also useful in bringing together diverse information on the synthesis and hypothetical functions of growth-inhibitory substances.

There are, however, many shortcom- of living systems can be explained by the behaviour of their constitutive molecules and their appearance by physicochemical phenomena.

J. Tonnelat

J. Tonnelat is Professor of Physicochemical Biology at the Université de Paris-Sud, Orsay, France.

ings. The background literature is only referred to when the conclusions favour the case being made. Also, doctrines which are currently under question in the West (for example, the Cholodny-Went theory of tropisms, the gene expression theory of phytochrome action, and the presumed control of transcription by auxins and gibberellins) are presented as established fact. Critical analysis of data is practically non-existent. This book seeks to make a case, not to present a reasoned and unbiased account. Thus, only the reader himself can judge whether it is successful. Personally I remain unconvinced.

H. Smith

H. Smith is Professor of Plant Physiology at the University of Nottingham, UK.

SENSORY

WORLD

Hallmark

of

\section{reporting}

A quarterly communicating significant factors in sensory and contiguous areas

\section{Brings you}

Papers - research reports of highest calibre

Developments - innovative work as it happens

World Literature - comprehensive spectrum of references, by schedule

$\$ 18 /$ year; overseas $\$ 20$ (outside USA add $\$ 2.80$ )

\section{P.O. Box 270, Lusby,} MD 20657, USA

Circle No. 24 on Reader Enquiry Card. 